OPEN ACCESS

Edited by:

Jens Staal,

Ghent University, Belgium

Reviewed by:

Ryohei Thomas Nakano,

Max Planck Institute for Plant Breeding Research (MPG), Germany

Fei Gao,

University of Arkansas, United States

*Correspondence: III-Sup Nou nis@sunchon.ac.kr

Specialty section:

This article was submitted to Plant Microbe Interactions,

a section of the journal

Frontiers in Plant Science

Received: 27 July 2017 Accepted: 28 September 2017 Published: 12 October 2017

Citation:

Robin AHK, Yi G-E, Laila R, Hossain MR, Park J-I, Kim HR and

Nou I-S (2017) Leptosphaeria maculans Alters Glucosinolate Profiles

in Blackleg Disease-Resistant and -Susceptible Cabbage Lines.

Front. Plant Sci. 8:1769.

doi: 10.3389/fpls.2017.01769

\section{Leptosphaeria maculans Alters Glucosinolate Profiles in Blackleg Disease-Resistant and -Susceptible Cabbage Lines}

\author{
Arif Hasan Khan Robin ${ }^{1,2}$, Go-Eun Yi ${ }^{1}$, Rawnak Laila ${ }^{1}$, Mohammad Rashed Hossain ${ }^{1,2}$, \\ Jong-In Park ${ }^{1}$, Hye R. Kim ${ }^{3}$ and III-Sup Nou ${ }^{1 *}$ \\ ${ }^{1}$ Department of Horticulture, Sunchon National University, Suncheon, South Korea, ${ }^{2}$ Department of Genetics and Plant \\ Breeding, Bangladesh Agricultural University, Mymensingh, Bangladesh, ${ }^{3}$ Plant Systems Engineering Research Center, \\ Korea Research Institute of Bioscience and Biotechnology, Daejeon, South Korea
}

Blackleg, a fungal disease caused by Leptosphaeria maculans, is one of the most devastating diseases of Brassica crops worldwide. Despite notable progress elucidating the roles of glucosinolates in pathogen defense, the complex interaction between $B$. oleracea (cabbage) and L. maculans infection that leads to the selective induction of genes involved in glucosinolate production and subsequent modulation of glucosinolate profiles remains to be fully understood. The current study was designed to identify glucosinolate-biosynthesis genes induced by $L$. maculans and any associated alterations in glucosinolate profiles to explore their roles in blackleg resistance in 3-month-old cabbage plants. The defense responses of four cabbage lines, two resistant and two susceptible, were investigated using two L. maculans isolates, 03-02 s and 00-100 s. A simultaneous increase in the aliphatic glucosinolates glucoiberverin (GIV) and glucoerucin (GER) and the indolic glucosinolates glucobrassicin (GBS) and neoglucobrassicin (NGBS) was associated with complete resistance. An increase in either aliphatic (GIV) or indolic (GBS and MGBS) glucosinolates was associated with moderate resistance. Indolic glucobrassicin (GBS) and neoglucobrassicin (NGBS) were increased in both resistant and susceptible interactions. Pearson correlation showed positive association between GER content with GSL-OH (Bo/033373) expression. Expressions of MYB34 (Bol007760), ST5a (Bol026200), and CYP81F2 (Bol026044) were positively correlated with the contents of both GBS and MGBS. Our results confirm that $L$. maculans infection induces glucosinolate-biosynthesis genes in cabbage, with concomitant changes in individual glucosinolate contents. In resistant lines, both aliphatic and indolic glucosinolates are associated with resistance, with aliphatic GIV and GER and indolic MGBS glucosinolates particularly important. The association between the genes, the corresponding glucosinolates, and plant resistance broaden our molecular understanding of glucosinolate mediated defense against $L$. maculans in cabbage.

Keywords: blackleg disease, Leptosphaeria maculans, glucosinolates, resistance, cabbage, expression analysis 


\section{INTRODUCTION}

Blackleg is one of the most devastating diseases of Brassica crop species, causing an estimated $\$ 900$ million of crop losses throughout the world every year (Howlett, 2004; Fitt et al., 2006, 2008). Blackleg is caused by the hemi-biotrophic fungal pathogen Leptosphaeria maculans. Severe blackleg infection can result in complete loss of Brassica napus canola or oilseed rape crops ( $\mathrm{Li}$ et al., 2003; Rouxel et al., 2003; Sprague et al., 2006). Blackleg is similarly devastating for vegetable varieties of $B$. oleracea, including cabbage (Humpherson-Jones, 1985; Rico et al., 2001; Dilmaghani et al., 2010, 2013; Piliponyte-Dzikiene et al., 2015); in fact, the first report of a blackleg epidemic in cabbage (in Wisconsin, USA) is almost a century old (Henderson, 1918). Despite the availability of various chemical control measures (Del Rio and Ruud, 2013; Fraser et al., 2016; Koh et al., 2016), development of effective resistance through breeding remains the most widely accepted means of protecting Brassica germplasm.

In addition to race-specific resistance conferred by $R$ genes, secondary metabolites produced by the plants also offer more general resistance against pathogens and insects (Wink, 1988; Giamoustaris and Mithen, 1997; Tierens et al., 2001; Brader et al., 2006; Lattanzio et al., 2006). Glucosinolates are Sulfurand nitrogen-containing secondary metabolites that are the precursors of isothiocyanates and sulforaphane, which have been found to play roles in plant resistance to insect pests and pathogens (Hogge et al., 1988; Mithen et al., 1995; Benderoth et al., 2006; Hopkins et al., 2009). Aliphatic and indolic glucosinolates are the two most important types of glucosinolates present in the Brassicaceae family (Fahey et al., 2001; Mithen, 2001; Bekaert et al., 2012). Breakdown products of both aliphatic and indolic glucosinolates produced through hydrolysis by endogenous myrosinases ( $\beta$-thioglucoside glucohydrolases) have anti-fungal properties in plants (Chew, 1988; Giamoustaris and Mithen, 1995; Manici et al., 1997; Agerbirk et al., 1998; Brader et al., 2001; Tierens et al., 2001; Barth and Jander, 2006; Stotz et al., 2011; Calmes et al., 2015).

The relationship between glucosinolate levels and the resistance of Brassicaceae family members to diverse fungal pathogens remains unclear. Upon L. maculans infection, overall levels of glucosinolates are not strongly correlated with pathogen resistance in different Brassica species (Mithen and Magrath, 1992; Sexton et al., 1999). In fact, a negative correlation between Alternaria infection and glucosinolate levels was reported in Brassica napus (Doughty et al., 1991; Giamoustaris and Mithen, 1997). By contrast, upon Sclerotinia sclerotiorum infection, the extent of pathogen-induced accumulation of indolic glucosinolates in Brassica napus is positively correlated with plant resistance (Li et al., 1999). These seeming contradictions could reflect the lifestyles of the individual fungal pathogens, e.g., necrotrophic versus biotrophic (Sanchez-Vallet et al., 2010), their host ranges, e.g., Brassicaceae-specialist versus broad-spectrum (Buxdorf et al., 2013), the genetic purity of the host plants, e.g., isogenic versus heterozygous lines, in addition to the range and quantity of glucosinolates and their break-down products produced by the host plants.
The association between total glucosinolate content and plant resistance to $L$. maculans infection has been studied since the 1990's. Nevertheless, no obvious relationship between glucosinolate profiles and L. maculans resistance has been established, possibly due to the fact that these studies focused on total glucosinolate levels rather than individual glucosinolate compounds (Mithen and Magrath, 1992; Giamoustaris and Mithen, 1997; Sexton et al., 1999; Kliebenstein et al., 2002). Previous studies concluded that the glucosinolate-myrosinase system is not a major determinant of blackleg resistance (Wretblad and Dixelius, 2000; Andreasson et al., 2001). This conclusion was supported by an earlier report in resynthesized $B$. napus $\mathrm{F}_{2}$ progeny, in which disease resistance and glucosinolate profiles did not co-segregate (Mithen and Magrath, 1992). By contrast, infection with the hemibiotrophic fungus L. maculans was shown to trigger the accumulation of both aliphatic (gluconapin, i.e., 3-butenyl glucosinolate; progoitrin, i.e., 4hydroxybutyl glucosinolate; glucobrassicanapin, i.e., 4-pentenyl glucosinolate; and gluconapoleiferin, i.e., 2-hydroxy-4-pentenyl glucosinolate) and indolic (glucobrassicin, i.e., 3-indolylmethyl glucosinolate and 4-hydroxy-glucobrassicin) glucosinolates in Brassica rapa (Abdel-Farid et al., 2010). A few recent reports have shown that resistance to obligate biotrophs, hemibiotrophs, and necrotrophs might be associated with the production of indolic glucosinolates in Brassicaceae (Bednarek et al., 2009; Hiruma et al., 2013). In Arabidopsis, accumulation of indolic 4-methoxy-glucobrassicin in response to fungal attack was regulated by the expression of CYP81F2, which is activated by the myrosinase PEN2 (Bednarek et al., 2009). These contrasting reports on the association of glucosinolate profiles and resistance in Brassica species call for further investigation of plant-pathogen interactions at the molecular and biochemical levels.

Our previous studies have shown that the upregulation of glucosinolate biosynthesis genes is associated with the upregulation of individual glucosinolate compounds in $B$. oleracea inbred lines (Robin et al., 2016; Yi et al., 2016). Here, we investigate changes in expression of genes associated with glucosinolate biosynthesis upon infection with $L$. maculans and correlate these changes with alterations in glucosinolate profiles. These experiments were performed in both resistant and susceptible genotypes against two different $L$. maculans isolates.

\section{MATERIALS AND METHODS}

\section{Plant Materials and Growth Conditions}

Seeds of four cabbage inbred lines (B. oleracea var. capitata) were obtained from Asia Seeds Ltd. (Seoul, South Korea). Two of the lines were reported to be resistant to blackleg disease at the seedling stage and the other two were susceptible (Figure 1; Robin et al., 2017a). Seeds were sown in a gardensoil mixture composed of peat moss, coco peat, perlite, zeolite, and vermiculite in 32-celled trays in a plant culture room with a temperature of $20 \pm 2^{\circ} \mathrm{C}$, 16-h day-length, and a light intensity of ca. $400 \mu \mathrm{mol} \mathrm{m}^{-2} \mathrm{~s}^{-1}$ at bench level (florescent light bulbs; Yi et al., 2015). Seedlings were grown for four weeks before transfer to a glasshouse, where they were grown for another two months before infection with L. maculans. 


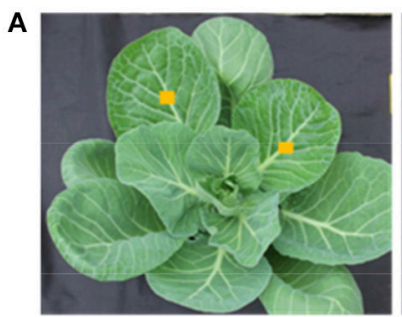

BN4059

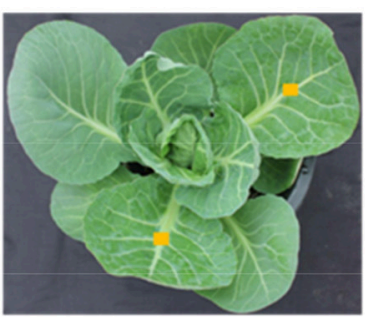

BN4072

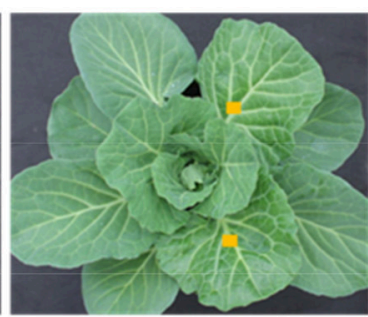

BN4098

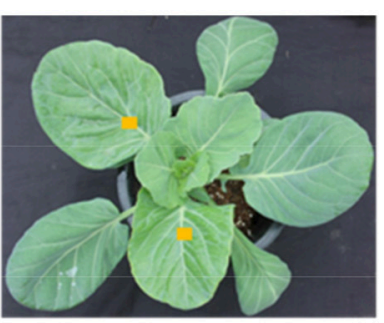

BN4303

\section{Cabbage genotypes}

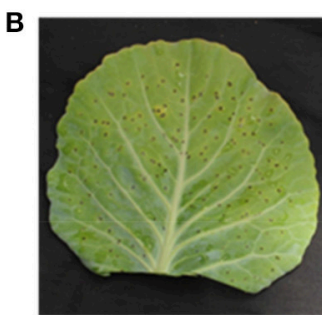

Score 1

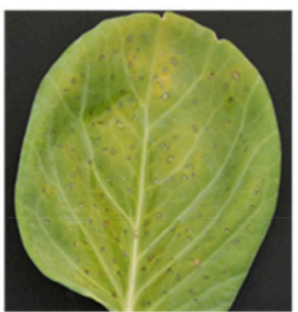

Score 3

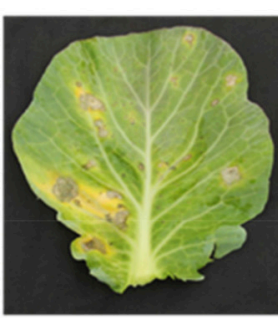

Score 5

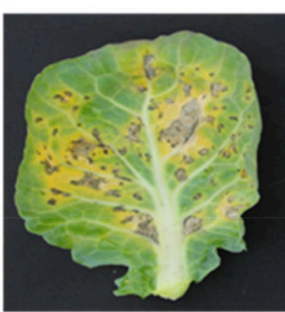

Score 7

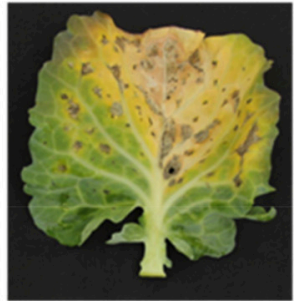

Score 9

\section{Scoring criteria}

FIGURE 1 | Cabbage lines (A) and scoring criteria (B) against blackleg disease. Three-month-old cabbage plants were inoculated to test their response to two Leptosphaeria maculans isolates 03-02s and 00-100 s. Middle-aged leaves with yellow squares were infected. Infected leaves were scored two weeks after inoculation on a scale from 1-9 based on visual scoring criteria, where a score of "1" represents the least infected and "9" represents the most infected cabbage plants. In our previous assessment of seedling resistance, the lines BN4059 and BN4072 were susceptible while BN4098 and BN4303 were resistant (Robin et al., 2017a).

\section{L. maculans Isolates and Inoculation}

Details of the two fungal isolates, culture methods, and spore solution preparation have been previously published (Robin et al., 2017a). In brief, two isolates of L. maculans, 03-02s (AvrLm1-4-6-7-11-J1-S, AvrLep1-2-3) and 00-100s (AvrLm2-3-69-J1-S, AvrLep1-2), were provided by Agriculture and Agri-Foods (AAFC), Saskatoon, Canada. Each isolate was sub-cultured on $20 \% \mathrm{~V} 8$ agar plates and grown at $22^{\circ} \mathrm{C}$ with a 16 -h photoperiod under fluorescent light to produce a fungal inoculum. After 10 days, each plate was flooded with $10 \mathrm{~mL}$ of sterile distilled water and scraped with a sterile microscope slide to prepare a spore suspension. The spore suspension was filtered using sterile Miracloth (EMD Millipore Corporation, USA) to remove the mycelia and other debris. The clear suspension was centrifuged to concentrate the spores. The spore suspensions of 03-02 s and $00-100 \mathrm{~s}$ isolates were then diluted to $2.25 \times 10^{7}$ spores $\mathrm{mL}^{-1}$ and used to inoculate small wounds created on middleaged leaves of 3-month-old cabbage plants (Figure 1A). The experiment was laid out using a randomized block design with six plants per isolate. Approximately four wounds were created per $\mathrm{cm}^{2}$ leaf area. A set of six plants were kept as controls and another six plants were wounded but not infected (mock-treated). Diseased areas on the leaf surface were scored two weeks after inoculation on a scale of $1-9$, based on the severity of the infection (Figure 1B), and categorized as resistant ( $\mathrm{R}$, score range 1.0-3.0), moderately resistant (MR,
3.1-6.0), susceptible (S, 6.1-7.0) and highly susceptible (HS, 7.1-9.0).

\section{Collection and Preparation of Leaf Samples for HPLC and Expression Analysis} Leaf samples from three biological replicates, randomly chosen from six inoculated plants, were collected from control, mocktreated, and L. maculans inoculated plants four days after inoculation to estimate endogenous glucosinolate content and quantify the expression of selected genes from the glucosinolate biosynthesis pathway (Figure S1). Leaf samples collected for HPLC analysis and real-time PCR were immediately stored at $-80^{\circ} \mathrm{C}$ after flash-freezing in liquid nitrogen.

\section{Estimation of Glucosinolate Content}

Leaf samples from three biological replicates from each of the control, mock, and L. maculans infected plants were used for extracting desulfo-glucosinolates through a modified HPLC protocol as previously described (Yi et al., 2015, 2016; Robin et al., 2016). Frozen leaf tissue stored at $-80^{\circ} \mathrm{C}$ was treated with methanol and then ground to a fine powder. The powdered leaf samples were preserved at $70^{\circ} \mathrm{C}$ for $10 \mathrm{~min}$ and then kept at room temperature for about an hour. The powdered samples were then centrifuged at $10,000 \times g$ at $4^{\circ} \mathrm{C}$ for $8 \mathrm{~min}$. This centrifugation step removes structural components and protein molecules as sediments. The supernatant was then passed 
over an anion-exchange column. Centrifugation and anionexchange chromatography was repeated two more times. The supernatant collected from the final step of anion-exchange chromatography was considered the crude glucosinolate sample. The crude glucosinolates were then subjected to desulfation. Here, $0.5 \mathrm{~mL} 50 \mathrm{mM}$ barium acetate and $0.5 \mathrm{~mL} 50 \mathrm{mM}$ lead acetate were mixed with the crude glucosinolates followed by centrifugation at $2,000 \times g$ for $10 \mathrm{~min}$. The supernatant was then passed through a pre-equilibrated (with $0.5 \mathrm{M}$ sodium acetate) DEAE-Sephadex column. Desulfation was initiated by the addition of $250 \mu \mathrm{L}$ aryl sulfatase to the column and was allowed to run over-night for $16 \mathrm{~h}$. The desulfated glucosinolates were then eluted with $1 \mathrm{~mL}$ distilled water. The eluted desulfoglucosinolates were purified by high-speed centrifugation at $20,000 \times g$ for $4 \mathrm{~min}$ at $4^{\circ} \mathrm{C}$ followed by filtering through a PTFE filter ( $13 \mathrm{~mm}, 0.2 \mu \mathrm{m}$, Advantec, Pleasanton, CA, USA). The purified glucosinolates were then subjected to HPLC analysis in a Waters 2695 HPLC system (Waters, Milford, MA, USA) equipped with a $\mathrm{C}_{18}$ column (Zorbax Eclipse XBD $\mathrm{C}_{18}, 4.6 \mathrm{~mm}$ $\times 150 \mathrm{~mm}$, Agilent Technologies, Palo Alto, CA, USA). Both water and acetonitrile were used as mobile phase solvents. Individual glucosinolate compounds were detected using a PDA 996 UV-visible detector (Waters) at a wavelength of $229 \mathrm{~nm}$. For quantification of the detected glucosinolates, a standard curve prepared from commercial sinigrin (SIN) was used. Mass spectrometry analysis (HPLC/MS, Agilent 1,200 series, Agilent Technologies) facilitated the identification of individual glucosinolates (Yi et al., 2016). Chemical names, common names, abbreviations, and chemical structures of the glucosinolates identified in this study are given in Figure S2.

\section{Primer Design for Expression Analysis of Glucosinolate Biosynthesis Genes}

Thirty-eight genes involved in glucosinolate biosynthesis were selected for transcription analysis to determine how transcript levels are affected by pathogen inoculation (Table S1, Figure S1). Eleven of the genes encode transcription factors: five in the aliphatic biosynthesis pathway and six in the indolic pathway. Of the other 27 genes, 10 are aliphatic biosynthesis genes and 17 are indolic biosynthesis genes (Robin et al., 2016; Yi et al., 2016). Primers were designed using primer3plus software (http:// primer3plus.com/) and primer efficiency was tested according to Robin et al. (2016).

\section{cDNA Synthesis and Real-Time Quantitative PCR Analysis}

Total RNA was extracted from the collected leaf samples using RNeasy mini kit, Catalog No. 74106, Qiagen, Valencia, CA, USA. cDNA synthesis was performed from total RNA using a PrimeScript-based kit (Takara Bio, Inc., Shiga, Japan). To conduct quantitative RT-PCR (qPCR), iTaqTM SYBR ${ }^{\circledR}$ Green Super-mix was used with ROX (Bio-Rad, Hercules, CA, USA). For each reaction, a total reaction volume of $20 \mu \mathrm{L}$ was prepared containing $10 \mu \mathrm{L}$ PCR master mix, $7 \mu \mathrm{L}$ ultra-pure water, $2 \mu \mathrm{L}$ forward and reverse primers and $1 \mu \mathrm{L}$ cDNA template with a concentration of $60 \mathrm{ng} \mu \mathrm{L}^{-1}$. PCR conditions were as follows: denaturation at $95^{\circ} \mathrm{C}$ for $10 \mathrm{~min}, 40$ cycles of amplification with denaturation at $95^{\circ} \mathrm{C}$ for $20 \mathrm{~s}$, annealing at $58^{\circ} \mathrm{C}$ for $20 \mathrm{~s}$, and amplification and signal acquisition at $72^{\circ} \mathrm{C}$ for $30 \mathrm{~s}$. Data were recorded as fluorescence at the end of each of 40 cycles for each sample. Each biological replicate was tested in three technical replicates. Quantification $(\mathrm{Cq})$ analysis was done using LightCycler96 software (Roche, Mannheim, Germany). Livak's comparative $2^{-\Delta \Delta \mathrm{Ct}}$ method was used to calculate the relative expression of each sample (Livak and Schmittgen, 2001). Three different actin genes selected from the NCBI database, GenBank Accession Nos. AF044573 (Zhang et al., 2012), JQ435879 (Nawaz et al., 2014), and XM_013753106 (Lee et al., 2015), were expressed in all inbred lines and were used as a reference.

\section{Statistical Analysis}

A one-way analysis of variance was conducted to test the statistical significance of different treatments on the four cabbage inbred lines using Minitab 18 statistical software (Minitab Inc., State College, PA, USA). A posthoc Tukey's pairwise comparison was conducted to visualize statistical significance of 16 treatment $\times$ genotype combinations. Test statistic, degrees of freedom, and $\mathrm{p}$-values of statistical significance for glucosinolate contents and relative expression of biosynthesis genes are given in Table S2.

Separate heat maps were drawn to show association between blackleg scores and glucosinolate contents or expression of genes using conditional formatting option in Microsoft Excel. Pearson correlation coefficient was estimated between glucosinolate content and expression of biosynthesis genes in 16 treatment $\times$ genotype combinations (Supplementary Appendix 1).

\section{RESULTS}

\section{Resistance of Adult Cabbage Lines to $L$. maculans Infection}

Inoculation of cabbage leaves with two L. maculans isolates resulted in different responses in different lines, based on visual scoring of blackleg disease symptoms (Table 1). Of the eight total combinations of four cabbage genotypes and two isolates (as shown in Table 1) only one combination, BN4303 $\times 00-100$ s, exhibited complete resistance, with the lowest visual score of 2 (range 1-3). The combinations of BN4303 × 03-02 s (score range $3-5$ ) and BN4098 $\times 00-100$ s (score range 4-6) showed moderate resistance. $\mathrm{BN} 4098$, which exhibited moderate resistance to isolate 00-100 s, was susceptible to isolate 03-02 s (score range 68). Lines BN4072 and BN4059 were susceptible to both isolates, with the latter being highly susceptible to both isolates (Table 1). Overall, line BN4303 was the most resistant, as it showed complete resistance to isolate $00-100 \mathrm{~s}$ and moderate resistance to $03-02 \mathrm{~s}$, whereas BN4098 showed moderate resistance only to isolate $00-100 \mathrm{~s}$ and the other two lines were susceptible.

\section{Constitutive Glucosinolate Contents Vary in Cabbage Inbred Lines}

In untreated control plants, levels of both aliphatic and indolic glucosinolates varied significantly between the four cabbage lines (Figure 2, Supplementary excel data file). Among the control plants, BN4059, the most susceptible cabbage line, had the 
TABLE 1 | Resistance scoring of four cabbage lines at three months of age (adult stage) against two L. maculans isolates "03-02 s" and "00-100 s" 15-days post-inoculation.

\begin{tabular}{|c|c|c|c|c|c|c|c|}
\hline \multirow[t]{3}{*}{ Line } & \multirow{3}{*}{$\begin{array}{l}\text { Seedling resistance } \\
\text { status against both } \\
\text { isolates }\end{array}$} & \multicolumn{6}{|c|}{ L. maculans isolates } \\
\hline & & \multicolumn{3}{|c|}{$03-02 \mathrm{~s}$} & \multicolumn{3}{|c|}{$00-100 \mathrm{~s}$} \\
\hline & & Score & Score range & Interaction & Score & Score range & Interaction \\
\hline BN4059 & HS & 9.0 & $7-9$ & HS & 8.0 & $6-9$ & HS \\
\hline BN4072 & HS & 7.0 & $6-8$ & S & 7.0 & $7-9$ & S \\
\hline BN4098 & $\mathrm{R}$ & 7.0 & $6-8$ & S & 5.0 & $4-6$ & MR \\
\hline BN4303 & $\mathrm{R}$ & 4.0 & $3-5$ & MR & 2.0 & $1-3$ & $\mathrm{R}$ \\
\hline
\end{tabular}

Each score is the median of six observations. R, Resistant; MR, moderately resistant; S, susceptible and HS, highly susceptible.

highest total levels of glucosinolates while BN4303, the most resistant line, had the lowest total levels (Figure S3). PRO was found only in BN4059, which also had the highest levels of aliphatic glucoiberin (GIB), sinigrin (SIN), and glucoiberverin (GIV), but no glucoerucin (GER). BN4059 also had the highest levels of indolic GBS and MGBS, but no NGBS. Notably, BN4303 had the lowest levels of SIN between the four lines. Hydroxy-glucobrassicin (HGBS), another indolic glucosinolate, was detected only in untreated control plants of the BN4098 line (Figure S3).

\section{L. maculans Inoculation Alters the Glucosinolate Profile of Adult Cabbage Plants}

Inoculation of 3-month-old cabbage plants with either of the two L. maculans fungal isolates remarkably changed the glucosinolate profiles in leaves of the fully and moderately resistant cabbage lines. The content of aliphatic GIV increased significantly in BN4303 in response to both fungal isolates while it decreased or was not produced in the susceptible genotypes BN4059 and BN4072 (Figure 2). In the resistant line BN4303, levels of GIV increased by 2.77- and 4.14-fold four days after inoculation with $03-02 \mathrm{~s}$ and 00-100 s, respectively compared to mock-treated plants (Figure 2). By contrast, in the most susceptible line BN4059, GIV levels decreased 3.72- and 6.28fold following fungal inoculation with 03-02s and 00-100s, respectively, compared to mock-treated plants (Figure 2).

Infection with $00-100 \mathrm{~s}$ induced the accumulation of glucoerucin (GER) in the resistant line BN4303; no GER was detected in control plants (Figure 2). The most susceptible line, BN4059, did not produce any glucoerucin (GER). Other notable changes in aliphatic glucosinolates were (i) a 3- to 8 -fold decrease in progoitrin (PRO) levels in mock-treated and fungal-inoculated plants in the susceptible cabbage line BN4059 compared to the untreated plants, indicating that PRO levels are sensitive to both leaf injury and fungal attack; (ii) accumulation of gluconapin (GNA) in BN4072 in response to 03-02 s infection and (iii) an increase in GER in mock-treated BN4303 plants compared to the untreated plants, indicating that GER levels are also sensitive to both leaf injury and fungal attack (as GER levels further increased in the same line upon 00-100 inoculation).
After inoculation of BN4303 with 00-100s, levels of glucobrassicin (GBS) and neoglucobrassicin (NGBS) increased by 2.65 - and 3.64-fold, respectively, compared to the mocktreated plants (Figure 2). Upon infection of the moderately resistant line BN4098 with 00-100 s, levels of GBS and methoxyglucobrassicin (MGBS) increased by 2.28- and 2.13-fold compared to the mock-treated plants, respectively (Figure 2).

In contrast to the resistance-related upregulation, indolic GBS content was increased in two susceptible interactions, BN4059 $\times$ 00-100s (1.52-fold) and BN4072 × 00-100s (2.06-fold), compared to the mock-treated plants (Figure 2). NGBS content was also increased in BN4059 $\times 00-100$ s (1.89-fold) compared to the mock-treated plants. In addition to GBS and NGBS, the aliphatic GIB content also increased 1.79-fold in BN4059 $\times 00-100 \mathrm{~s}$ interaction compared to the mock-treated plants (Figure 2).

Overall, our results show that the complete resistance of the line BN4303 against 00-100s isolate was associated with simultaneously increased contents of both aliphatic (GIV and GER) and indolic (GBS and NGBS) glucosinolates upon inoculation, while the enhanced accumulation of an aliphatic glucosinolate (GIV) was associated with moderate resistance in this line against $03-02 \mathrm{~s}$ isolate (Table 2). By contrast, the moderate resistance of the line BN4098 against the $00-100 \mathrm{~s}$ isolate was associated with enhanced accumulation of only indolic glucosinolates (GBS, NGBS and MGBS).

\section{Expression Changes in Transcription Factor and Aliphatic Glucosinolate Biosynthesis Genes in Cabbage Lines With Blackleg Disease}

The expression levels of majority of the transcription factors under untreated control conditions were comparatively higher in BN4098 compared to the other three lines (Figure S4, Supplementary excel data file). Like the transcription factor genes, the expression levels of most of the aliphatic structural biosynthesis genes were comparatively higher in BN4098 than in the other three cabbage lines under untreated control conditions (Figure 3, Figure S5). However, FMOGSOX2 (Bol010983) and FMOGS-OX5 (Bol029100) showed higher expression in BN4059 control plants compared to the other 


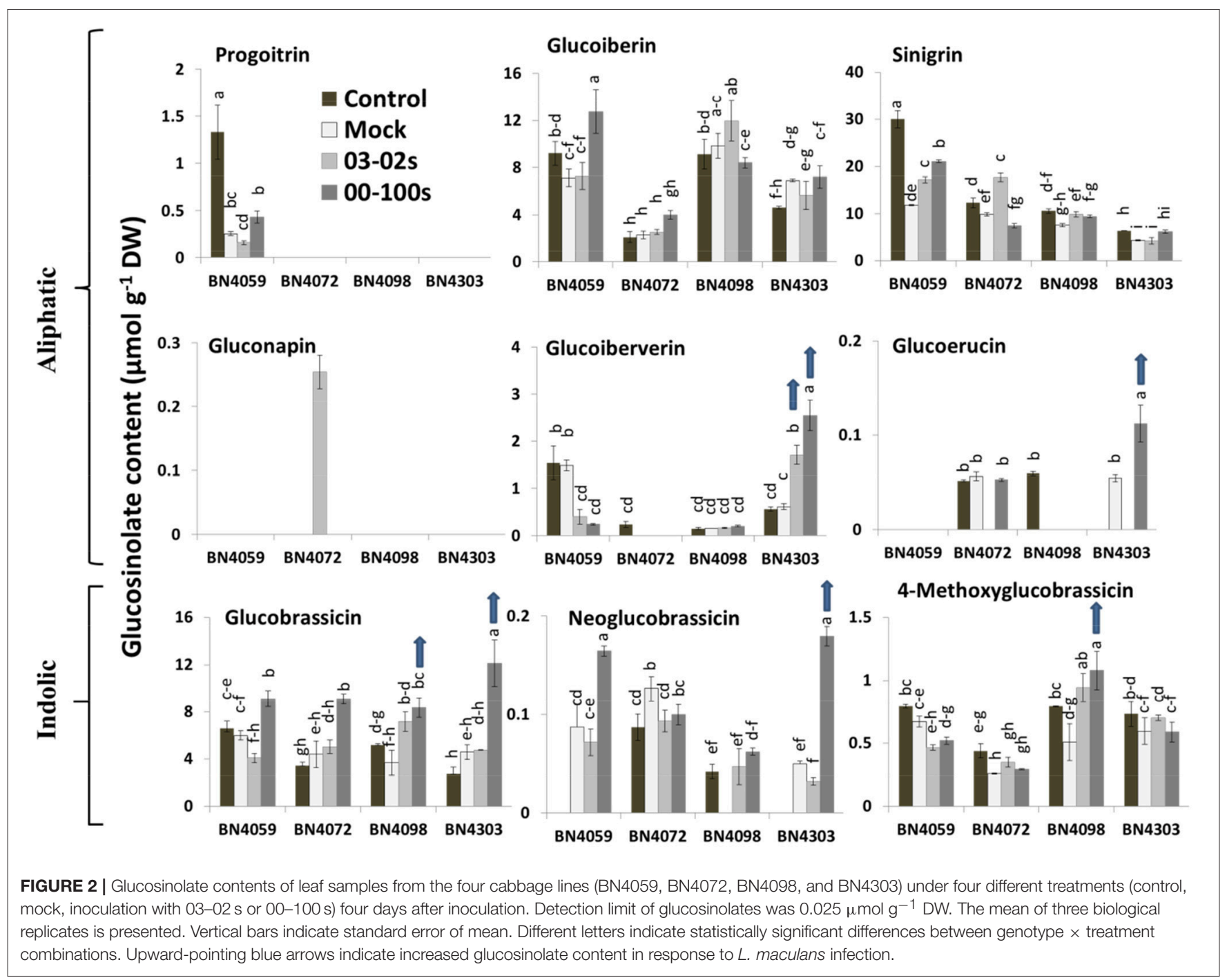

three lines, consistent with the highest content of total, and most individual, aliphatic glucosinolates in this genotype (Figure S5).

None of the genes for aliphatic transcription factors were upregulated in any resistance combination; rather, expression of these five genes generally decreased in this genotype upon infection (Figure S4). Expression of ST5b and GSL-OH, which are involved in the biosynthesis of aliphatic glucosinolates, increased in both of the resistant lines, BN4303 and BN4098, during blackleg infection (Figure 3). In the resistant line BN4303, expression of ST5b genes Bol026201 and Bol026202 increased, respectively, 4.31- and 2.73-fold after $00-100 \mathrm{~s}$ infection and 3.23 - and 1.70-fold after 03-02 s infection compared to mocktreated plants (Figure 3). Expression of GSL-OH increased 3.33fold in BN4303 after 00-100s infection compared to mocktreated plants. In susceptible combinations, BN4072 $\times 03-$ 02s and BN4098 $\times$ 03-02s, AOP2 (Bo2g102190) showed 24.4and 3.39-fold higher expression, respectively, compared to mock treated plants (Figure S5). AOP2 also showed a 2.7-fold increase in BN4303 $\times 03-02 \mathrm{~s}$ compared to mock treated plants (Figure S5).

\section{Expression Changes in Transcription Factors Involved in the Biosynthesis of Indolic Glucosinolates in Cabbage Lines with Blackleg Disease}

The expression levels of five $B$. oleracea genes encoding three transcription factors were measured under control, mock, and infection conditions. In untreated control plants, five out of six transcription factors involved in indolic glucosinolate biosynthesis, the exception being MYB34 (Bol036262), were highly expressed in BN4098 compared to the other three lines (Figure 4). The genes Bol007760 and Bol017062, encoding the transcription factor MYB34, showed increased expression in the resistant line BN4303 with blackleg disease. Bol007760 and Bol017062 showed a 9.35- and 2.13-fold increase against 00100 s isolates, respectively, compared to mock-treated plants 
TABLE 2 | Association between increased glucosinolate contents and increased expression of glucosinolate pathway genes in resistant and moderately resistant disease interactions.

\begin{tabular}{|c|c|c|c|}
\hline & $\begin{array}{l}\text { BN4098 x } \\
00-100 \text { s } \\
\text { (moderately } \\
\text { resistant } \\
\text { interaction) }\end{array}$ & $\begin{array}{l}\text { BN4303 x } \\
03-02 \text { s } \\
\text { (moderately } \\
\text { resistant } \\
\text { interaction) }\end{array}$ & $\begin{array}{l}\text { BN4303 x } \\
00-100 \mathrm{~s} \\
\text { (resistant } \\
\text { interaction) }\end{array}$ \\
\hline Aliphatic & - & $\begin{array}{l}\text { GIV } \\
\text { (ST5b-Bol026201, } \\
\text { Bol026202) }\end{array}$ & $\begin{array}{l}\text { GIV and GER } \\
(\text { ST5b-Bol026201, } \\
\text { Bol026202) } \\
\text { GSL-OH } \\
(\text { Bol033373) }\end{array}$ \\
\hline Indolic & $\begin{array}{l}\text { MGBS } \\
\text { (CYP81F4- } \\
\text { Bol032712, } \\
\text { CYP81F2- } \\
\text { Bol026044) }\end{array}$ & - & $\begin{array}{l}\text { GBS } \\
\text { (MYB34- } \\
\text { Bol007760, } \\
\text { ST5a-Bol026200) } \\
\text { NGBS } \\
\text { (CYP81F4- } \\
\text { Bol032712, } \\
\text { Bol032714; } \\
\text { CYP81F2- } \\
\text { Bol026044) }\end{array}$ \\
\hline
\end{tabular}

GIV, Glucoiberverin, GER, glucoerucin, GBS, glucobrassicin, NGBS, neoglucobrassicin and MGBS, methoxy-glucobrassicin.

(Figure 4). By contrast, MYB34 (Bol036262), and MYB122 (Bol026204) showed a 44.1- and 5.49-fold increase, respectively, in the susceptible line BN4072 under 03-02 s infection compared to mock-treated plants (Figure 4).

\section{Expression Changes in Indolic Glucosinolate Biosynthesis Genes in Cabbage Lines with Blackleg Disease}

In untreated control plants, two genes, CYP81F2 (Bol014239) and CYP81F3 (Bol028919), showed higher expression in BN4303 than in the other three lines. Five genes including CYP81F1 (Bol017375), CYP81F1 (Bol017376), CYP81F1 (Bol028914), CYP81F2 (Bol012237), and IGMT1 (Bol020663) showed higher expression in BN4072, which had higher NGBS contents than the other lines. In addition, ten genes showed higher expression in BN4098, in which the corresponding MGBS content was higher compared to the other three cabbage lines (Figure 5, Figure S6).

ST5a (Bol026200), CYP81F4 (Bol032712, Bol032714), and CYP81F2 (Bol026044), which are associated with indolic glucosinolate biosynthesis, were upregulated in resistant cabbage lines upon infection. ST5a (Bol026200) exhibited a 5.31- and 3.36-fold increase, respectively, in BN4303 in response to 00$100 \mathrm{~s}$ and 03-02 s compared to mock-treated plants (Figure 5, Figure S6). This gene also showed a 1.28-fold increase in BN4098 under 00-100s infection compared to the mock-treated plants (Figure 5). ST5a (Bol039395) showed 1.5- and 1.58-fold increased expression in BN4303 in response to 00-100 s and 03-02 s compared to mock-treated plants (Figure S6). CYP81F4 (Bol032712) showed a 2.7- and 3.29-fold increase in BN4098 and
BN4303, respectively, in response to 00-100 s compared to the mock-treated plants (Figure 5). CYP81F4 (Bol032714) showed a 4.16-fold increase in BN4303 under 00-100s infection compared to the mock-treated plants. CYP81F4 (Bol028918) showed 2.94fold higher expression in BN4303 $\times 00-100 \mathrm{~s}$ compared to the mock-treated plants (Figure S6). CYP81F3 (Bol032711) exhibited 2.05-, 2.47-, and 2.16-fold increases in expression in $\mathrm{BN} 4098 \times 00-100 \mathrm{~s}, \mathrm{BN} 4303 \times 03-02 \mathrm{~s}$ and BN4303 $\times 00-100 \mathrm{~s}$, respectively, compared to the mock-treated plants (Figure S6).

CYP81F2 (Bol026044) showed a 6.78- and 5.31-fold increase in BN4303 under 03-02s and 00-100s infection, respectively, and also showed a 5.89-fold increase in BN4098 under 00$100 \mathrm{~s}$ infection compared to the mock-treated plants (Figure 5). CYP81F2 (Bol014239) showed 8.05-fold higher expression in BN4098 $\times 00-100$ s compared to the mock-treated plants (Figure S6). CYP81F1 (Bol028913) displayed a 2.71- and 6.66-fold increase in BN4303 infected with 00-100s compared to the mock-treated plants (Figure S6).

Notably, increased expression of some indolic glucosinolate genes was also observed in susceptible plants. For example, ST5a (Bol026200) in the BN4098 $\times$ 03-02 s combination increased 3.24-fold, CYP81F2 (Bol026044) increased 9.21-fold in the BN4098 $\times$ 03-02 s combination and 6.91-fold in the BN4072 $\times$ 03-02 s combination (Figure 5). ST5a (Bol039395), CYP81F2 (Bol014239) and IGMT1 (Bol007029) increased 2.56-, 33.55-, and 4.43-fold, respectively, in BN4098 infected with 03-02 s compared to the mock-treated plants (Figure S6).

\section{Association Between Pathogen-Induced Upregulation of Pathway Genes and Accumulation of Corresponding Glucosinolates and the Plant's Resistance Status}

A heat map emphasized that the fold changes under pathogen inoculation compared to mock-treated samples in expression of genes involved in the biosynthesis of glucosinolates were often consistent with the blackleg resistance in the cabbage lines. For example, in the resistant line BN4303 under 00100 s infection when ST5b (Bol026201 and Bol026202) and GSL$\mathrm{OH}$ (Bol033373) expression was increased, the accumulation of two aliphatic glucosinolates GIV and GER was also increased (Figures 6A,B). Higher expression levels of the $S T 5 b$ genes Bol026201 and Bol026202 were associated with an increased content of aliphatic GIV in the moderately resistant interaction of BN4303 $\times 03-02$ s. However, Pearson correlation coefficients showed positive correlation only between GIV content and MYB28 (Bol007795) expression (Figure 7A). GER content exhibited a positive correlation with both MYB28 (Bol007795) and GSL-OH (Bol033373). In the BN4303 $\times 00-$ $100 \mathrm{~s}$ interaction, increased expression of MYB34 (Bol007760) and ST5a (Bol026200) was concomitant with higher levels of GBS, and upregulation of CYP81F4 (Bol032712, Bol032714) and CYP81F2 (Bol026044) was associated with increased NGBS content (Figures 6A,C). Pearson correlation tests indicated a positive association of GBS content with both MYB34 (Bol007760) and ST5a (Bol026200) expression along with that 


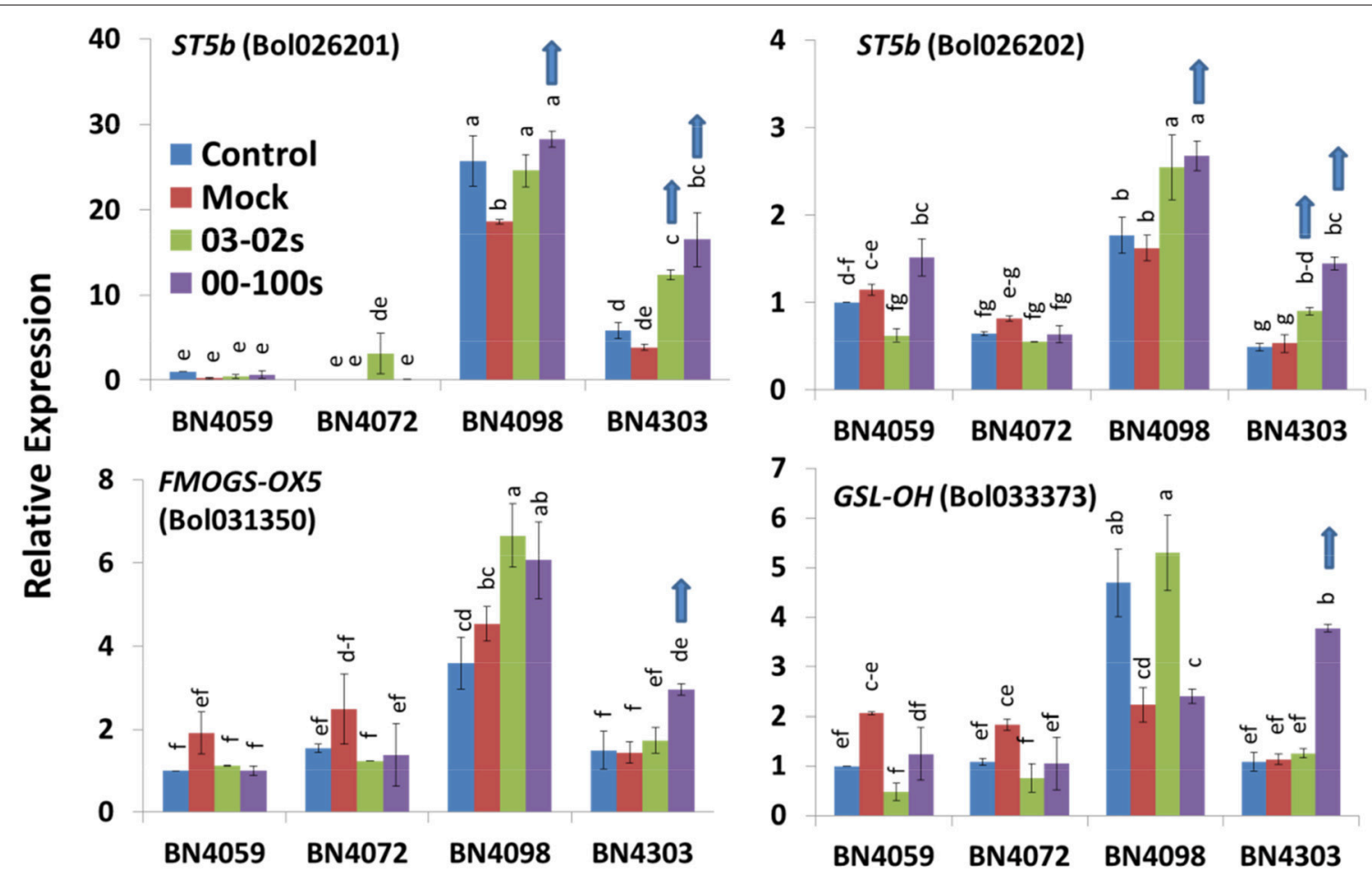

FIGURE 3 | Relative expression of aliphatic glucosinolate biosynthesis genes in leaf samples from the four cabbage lines (BN4059, BN4072, BN4098, and BN4303) under four different treatments (control, mock, inoculation with 03-02 s or 00-100 s) four days after inoculation. The mean of three biological replicates is presented. Vertical bars indicate standard error. Different letters indicate statistically significant differences between genotype $\times$ treatment combinations. Upward-pointing blue arrows indicate increased glucosinolate content in response to L. maculans infection.

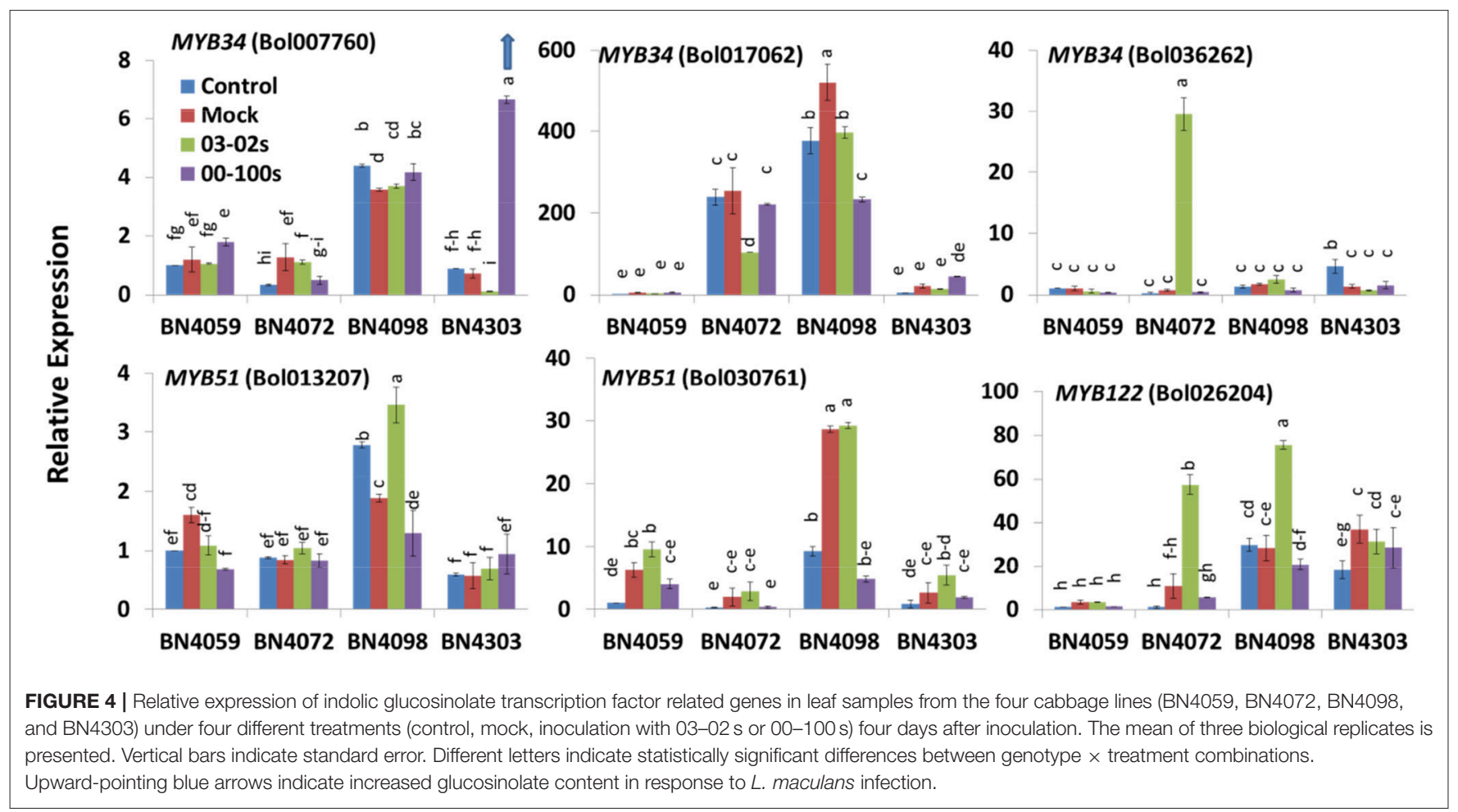




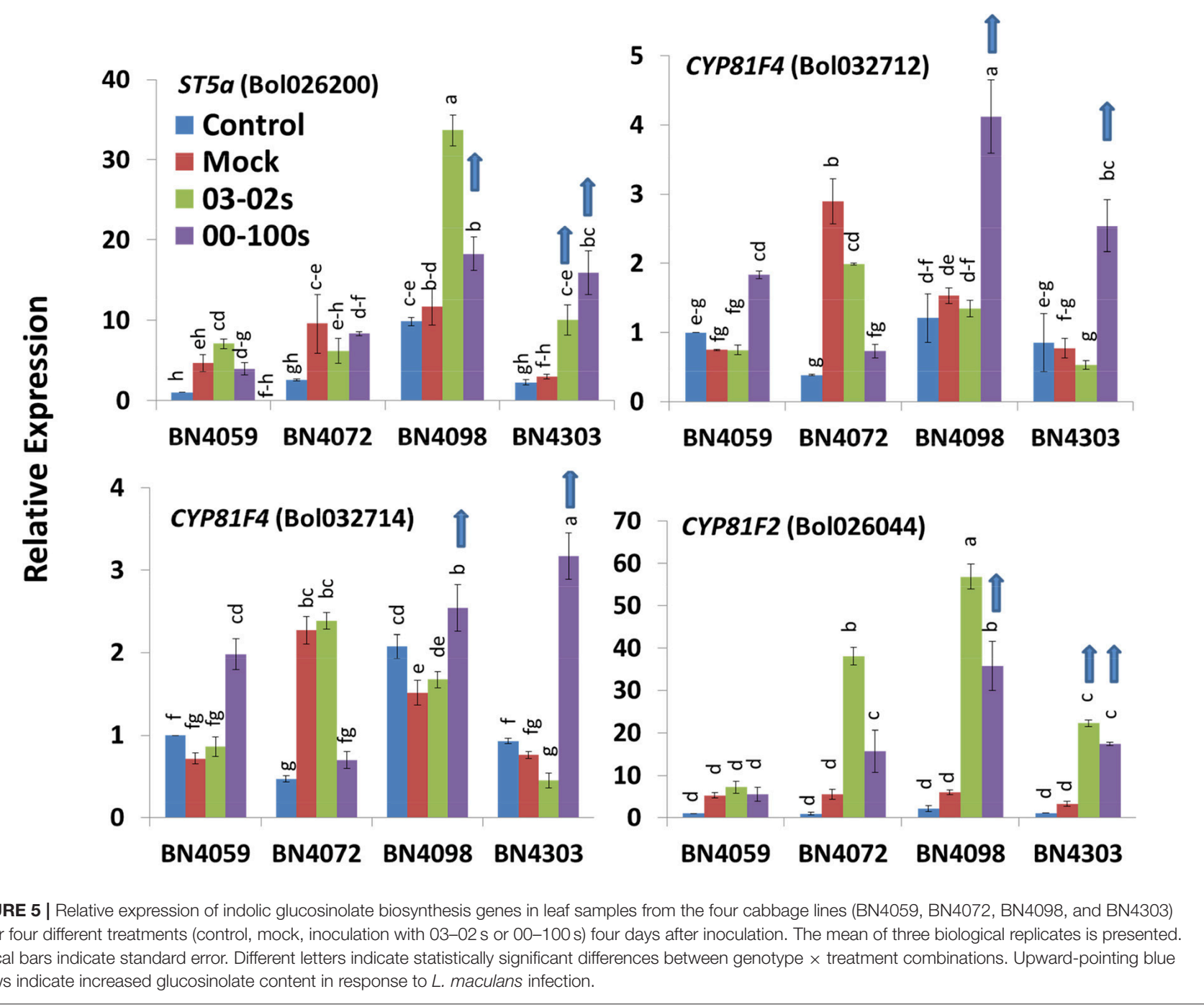

of CYP81F4 (Bol032712, Bol032714), CYP81F4 (Bol028918), and CYP81F2 (Bol026044). NGBS content showed a positive correlation with CYP81F4 (Bol032712, Bol032714) expression along with CYP81F4 (Bol028918), CYP81F1, and IGMT1 (Bol020663) expression (Figure 7B). In another moderately resistant interaction, BN4098 $\times 00-100 \mathrm{~s}$, increased expression of ST5a (Bol026200) corresponded to an increased content of GBS (Figures 6A,C). Furthermore, the increased expression of CYP81F4 (Bol032712, Bol032714) and CYP81F2 (Bol026044) corresponded with an increased content of MGBS. Among these three genes, MGBS content showed positive correlation only with CYP81F2 (Bol026044). In the susceptible interaction BN4059 $\times$ 00-100 s with increased content of GBS, expression of CYP81F4 genes was also increased (Figures 6A,C, 7B). These data demonstrate a connection between these genes and changes in the glucosinolate profiles of resistant plants in response to L. maculans infection although a few deviations are often noted.

\section{DISCUSSION}

\section{Resistance of Cabbage Inbred Lines Differs Between the Seedling and Adult Stages}

It has long been known that blackleg resistance in adult plants could be different from that in seedlings, as resistance at these stages has been reported to be under differing genetic control (Ballinger and Salisbury, 1996; Larkan et al., 2016). It was also reported that adult plant resistance is not race-specific (Rimmer, 2006), a conclusion that was later debated by other studies (e.g., Marcroft et al., 2012; Raman et al., 2012). Despite our previous findings that line BN4098 is resistant to both 03-02s and 00$100 \mathrm{~s}$ isolates at the seedling stage (Robin et al., 2017a), our current results show that is susceptible to $03-02 \mathrm{~s}$ at 3 months of age (Table 1). This difference in susceptibility-both at different growth stages and against different isolates of L. maculanscould be under genetic control, and will be a subject for further investigation. 


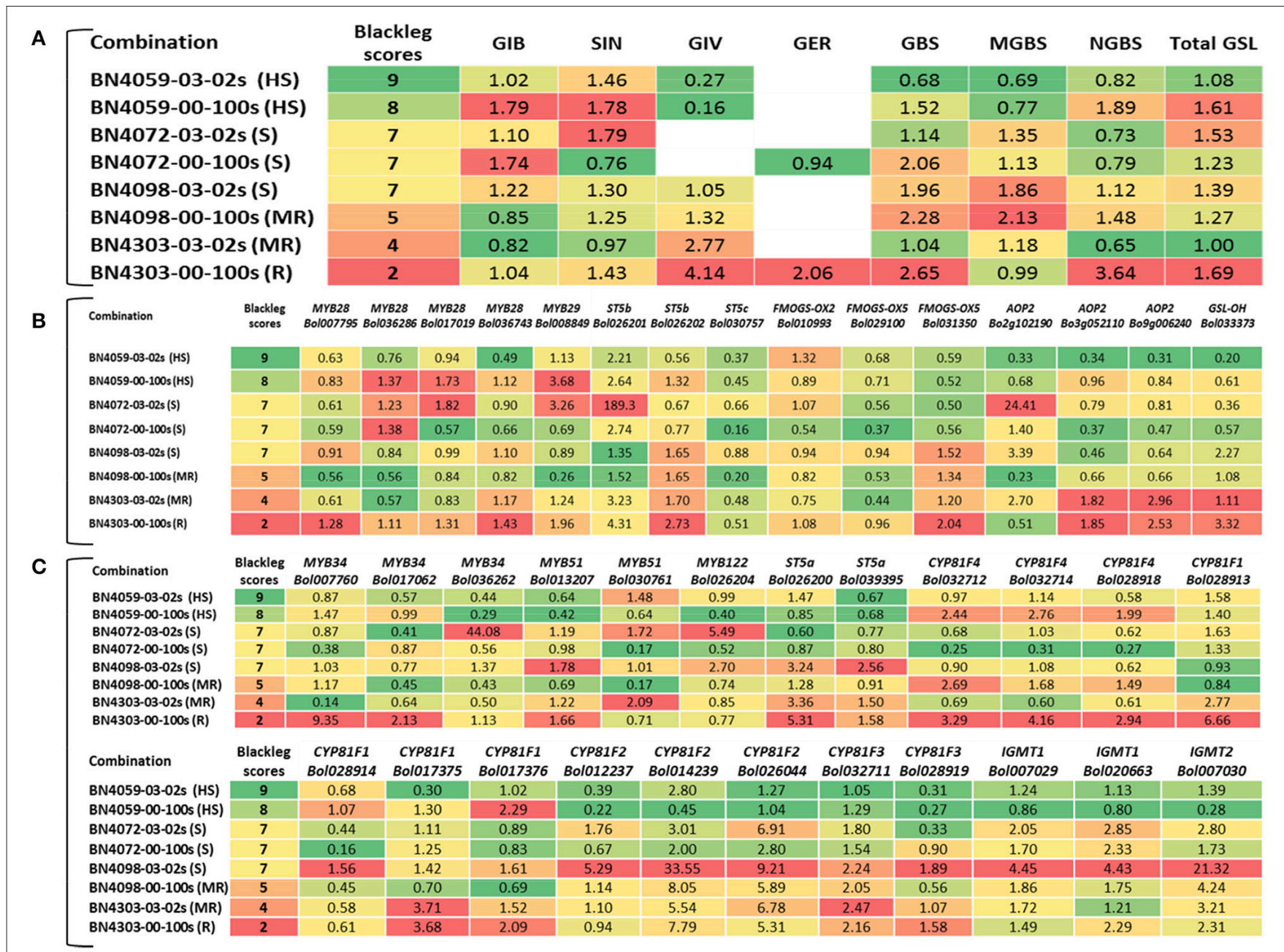

FIGURE 6 | Simple grouping assay in heat maps showing comparison between blackleg scores and (A) fold changes in glucosinolate contents, (B) fold changes in expression of aliphatic glucosinolate biosynthesis genes and (C) fold changes in expression of indolic glucosinolate-biosynthesis related genes in $L$.

maculans-inoculated leaf samples compared to respective mock-treated samples in HS, highly susceptible; S, susceptible; MR, moderately resistant and R, resistant combination. Red color represents blackleg disease resistance and increased accumulation of glucosinolates and expression of biosynthesis genes.

\section{The Aliphatic Glucosinolates GIV and GER and the Indolic Glucosinolates GBS and NGBS Are Associated with Resistance to Blackleg Disease}

Associations between pathogen induced glucosinolate accumulation and plant resistance were detectable for certain combination of compounds only under particular line $x$ pathovar combinations (Figure 6B). There were both positive and negative associations between glucosinolate abundance and resistance phenotypes. In addition, glucosinolate levels were often substantially altered under mock treatment compared to control plants. For instance, PRO and SIN contents were generally decreased in mock-treated plants compared to control plants in different line $\times$ pathovar combinations (Figure 2). However, the GIB, GIV, and GBS contents generally remained unaffected under mock treatment in different line $\times$ pathovar combinations compared to the control. We, therefore, considered glucosinolate level at the mock-treated samples as a benchmark to calculate pathogen-induced increase in accumulation. The contents of GBS and NGBS also exhibited upregulation in susceptible interactions in BN4059 and BN4072 (Figure 2). Aliphatic GIB and SIN contents were increased in BN4059 $\times$ 00-100 s combinations (Figure 2). Nevertheless, both aliphatic (glucoiberverin, glucoerucin) and indolic (glucobrassicin and neoglucobrassicin) glucosinolates increased to higher concentrations in the completely resistant line BN4303 upon blackleg infection (00-100 s isolate) (Table 2), indicating that resistance in adult cabbage plants may be achieved through an accumulation of both aliphatic and indolic glucosinolate compounds. These findings are somewhat different from current data that suggest indolic glucosinolates alone may provide resistance to nectrotrophic and hemibiotrophic pathogens (Sanchez-Vallet et al., 2010; Hiruma et al., 2013; Frerigmann 


\begin{tabular}{|c|c|c|c|c|}
\hline A & GIB & SIN & GIV & GER \\
\hline MYB28 (Bol007795) & 0.589 & 0.458 & 0.049 & -0.165 \\
\hline MYB28 (Bol036286) & 0.514 & 0.090 & 0.297 & 0.280 \\
\hline MYB28 (Bol017019) & 0.580 & -0.003 & -0.268 & -0.140 \\
\hline MYB28 (Bol036743) & 0.608 & -0.097 & -0.208 & -0.092 \\
\hline MYB29 (Bol008849) & 0.608 & -0.045 & -0.236 & -0.144 \\
\hline ST5b (Bol026201) & 0.455 & -0.369 & -0.015 & 0.025 \\
\hline ST5b (Bol026202) & 0.676 & -0.049 & -0.071 & -0.141 \\
\hline ST5C (Bol030757) & 0.303 & -0.094 & -0.351 & 0.016 \\
\hline FMOGS-OX2 (Bol010993) & 0.439 & 0.391 & -0.078 & -0.176 \\
\hline FMOGS-OX5 (Bol029100) & 0.186 & 0.308 & -0.116 & 0.072 \\
\hline FMOGS-OX5 (Bol031350) & 0.416 & -0.316 & -0.184 & -0.051 \\
\hline AOP2 (Bo2g102190) & -0.136 & 0.047 & -0.161 & -0.330 \\
\hline AOP2 (Bo3g052110) & 0.257 & 0.474 & -0.245 & -0.077 \\
\hline AOP2 (Bo9g006240) & 0.268 & 0.423 & -0.211 & -0.061 \\
\hline GSL-OH (Bol033373) & 0.442 & -0.281 & 0.086 & 0.305 \\
\hline
\end{tabular}

aliphatic glucosinolates and biosynthesis genes

B

\begin{tabular}{|l|c|c|c|}
\hline MYB34 (Bol007760) & 0.543 & 0.393 & 0.228 \\
\hline MYB34 (Bol017062) & -0.116 & 0.067 & -0.212 \\
\hline MYB34 (Bol036262) & -0.142 & -0.238 & 0.035 \\
\hline MYB51 (Bol013207) & 0.024 & 0.463 & -0.245 \\
\hline MYB51 (Bol030761) & -0.131 & 0.245 & -0.345 \\
\hline MYB122 (Bol026204) & 0.009 & 0.283 & -0.164 \\
\hline ST5a (Bolo26200) & 0.314 & 0.405 & 0.038 \\
\hline ST5a (Bol039395) & 0.122 & 0.424 & -0.132 \\
\hline CYP81F4 (Bol032712) & 0.401 & 0.226 & 0.339 \\
\hline CYP81F4 (Bol032714) & 0.507 & 0.110 & 0.483 \\
\hline CYP81F4 (Bol028918) & 0.336 & 0.166 & 0.352 \\
\hline CYP81F1 (Bol028913) & 0.213 & 0.405 & -0.052 \\
\hline CYP81F1 (Bol028914) & -0.072 & -0.498 & 0.398 \\
\hline CYP81F1 (Bol017375) & -0.059 & -0.672 & 0.327 \\
\hline CYP81F1 (Bol017376) & -0.139 & -0.651 & 0.333 \\
\hline CYP81F2 (Bol012237) & 0.065 & 0.071 & 0.110 \\
\hline CYP81F2 (Bol014239) & 0.220 & 0.398 & -0.058 \\
\hline CYP81F2 (Bol026044) & 0.318 & 0.334 & 0.061 \\
\hline CYP81F3 (Bol032711) & 0.223 & 0.644 & -0.219 \\
\hline CYP81F3 (Bol028919) & 0.150 & -0.033 & 0.177 \\
\hline IGMT1 (Bol007029) & 0.188 & 0.492 & -0.143 \\
\hline IGMT1 (Bol020663) & 0.101 & -0.584 & 0.400 \\
\hline IGMT2 (Bol007030) & 0.146 & 0.401 & -0.095 \\
\hline & & & \\
\hline
\end{tabular}

indolic glucosinolates and biosynthesis genes

FIGURE 7 | Heatmap showing correlation between the levels of aliphatic (A) and indolic (B) glucosinolates and expression of biosynthesis genes under four treatments in four cabbage lines. Blue letters represent statistically significant correlation $(p<0.05)$. For each gene and glucosinolate combination, the values indicate Pearson correlation coefficient. Green cells represent positive correlation and red cells represent negative correlation. GIB, Glucoiberin; SIN, sinigrin; GIV, glucoiberverin; GER, glucoerucin; GBS, glucobrassicin; NGBS, neoglucobrassicin; and MGBS, methoxyglucobrassicin. et al., 2016; Wu et al., 2016). The absence of a pathogeninduced increase in either aliphatic or indolic glucosinolates was associated with only moderate resistance in the BN4098 $\times 00-100 s$ and $\mathrm{BN} 4303 \times 03-02 \mathrm{~s}$ combinations, respectively (Table 2). By contrast, susceptible interactions exhibited an increase in one or only a few aliphatic or indolic glucosinolate compounds with a simultaneous decrease in other compounds. During infection of BN4059 for example, there was a significant increase of GIB, SIN, GBS, and NGBS but a decrease in aliphatic GIV and indolic MGBS, which may have resulted in this line's susceptibility to 00-100s (Figure 2). Furthermore, the marked upregulation of a single glucosinolate was also not associated with resistance. For example, GNA increased dramatically in BN4072 upon infection with 03-02 s, but neither aliphatic GIV nor any of the three indolic glucosinolates were induced, which may have resulted in this line's susceptibility to this isolate (Figure 2). These data suggest that specific glucosinolate profiles may confer resistance to cabbage to L. maculans infection in a genotype- and isolate-specific manner.

\section{Increased Expression of St5b Genes Led to Increased Levels of GER and GIV in Resistant Cabbage}

$S T 5 b$ genes are involved in secondary modifications of desulfoglucosinolates to GIB and GIV and then to other aliphatic glucosinolate compounds (Figure S1, Liu et al., 2014; Yi et al., 2015). In a recent study, increased expression of $S T 5 b$ genes was found to be associated with higher levels of three aliphatic glucosinolates, glucoraphanin, SIN, and GNA, which accumulated via GIB and GIV biosynthesis (Robin et al., 2016). In this study, infection of BN4303 with either 00$100 \mathrm{~s}$ or $03-02 \mathrm{~s}$ induced the expression of two ST5b genes, Bol026201 and Bol026202; infected plants also showed a striking increase in GIV and GER levels (Figure 6A). Thus, our results indicate that infection by the blackleg pathogen induced the upregulation of these genes, subsequently leading to the increase in GIV that was associated with the resistance of plants (Figures 2, 3). However, this correlation based association is required to be validated further through genetic studies.

\section{GIV Is a Candidate to Play a Crucial Role in Blackleg Disease Resistance}

The conspicuous contrasting patterns of GIV accumulation between the most resistant combination BN4303 $\times 00-100 \mathrm{~s}$, which showed high levels of GIV, and the most susceptible combinations BN4059 $\times 00-100 \mathrm{~s}$ and BN4059 $\times 03-02 \mathrm{~s}$, which showed low levels of GIV, highlight GIV as a potentially important contributor to glucosinolate-mediated resistance in adult cabbage plants (Figure 2). Moreover, a decrease in GIV levels upon infection in the two most susceptible combinations BN4059 $\times 03-02 s$ and BN4059 $\times 00-100$ s further indicated that lower GIV levels are associated with reduced plant resistance against blackleg infection (Figure 2). By contrast, in the modestly resistant combinations $\mathrm{BN} 4098 \times 00-100 \mathrm{~s}$ and 
BN4303 × 03-02s, GIV was completely absent and highly upregulated, respectively. This discrepancy indicates that GIV cannot provide full resistance alone, but rather is likely to be a contributor to resistance, possibly together with indolic GBS and NGBS (Figure 2). A higher accumulation of GIV coupled with GBS and NGBS was also found to show a positive association with lower feeding scores as reflected by less leaf area damage by the Diamondback moth in cabbage (Robin et al., 2017b).

\section{MYB34 Likely Activates Glucosinolate Biosynthesis Genes, Leading to Increases in GBS and NGBS in Cabbage Lines Resistant to Blackleg Disease}

Experimental evidence suggests that MYB34 genes directly regulate the biosynthesis of indolic glucosinolates in Arabidopsis thaliana (Frerigmann and Gigolashvili, 2014) and Brassica oleracea (Robin et al., 2016; Yi et al., 2016). MYB34 together with MYB51 and MYB122 provided resistance to the necrotrophic fungal pathogen Plectosphaerella cucumerina through the biosynthesis of indolic glucosinolates, where PEN2 plays a key role in activating indolic glucosinolates in response to pathogen attack (Frerigmann et al., 2016). MYB34 (Bol007760) is also induced in broccoli upon methyl jasmonate (MeJA) treatment which is a biotic elicitor that responds to jasmonic acid (JA) signaling (Yi et al., 2016). Likewise in this study, MYB34 genes Bol007760 and Bol017062 showed a 9.35- and 2.13-fold increase, respectively, upon inoculation with $00-$ $100 \mathrm{~s}$ in the resistant line BN4303 compared to mock-treated plants (Figure 4). Along with the corresponding increase in indolic glucosinolates, this indicates that MYB34 genes could play a role in the trans-activation of genes necessary for indolic glucosinolate biosynthesis in response to L. maculans infection (Figure 2). Consistent with our results, upregulation of MYB34 (Bol017062) in cabbage plants in a previous study was associated with the accumulation of indolic NGBS, which is a derivative of another indolic glucosinolate GBS (Robin et al., 2016).

Some notable MYB genes, MYB34 (Bol007760), MYB28 (Bol017019, Bol036743), and MYB29 (Bol008849), as well as other genes such as ST5b, ST5c and FMOGS-OX5 showed higher expression, in general, in BN4098 whereas CYP81F1 (Bol017375, BOl017376) genes showed comparatively higher expression in BN4072. However, these differences in expression did not lead to significant differences in glucosinolate accumulation of the respective indolic and aliphatic glucosinolates, i.e., glucosinolate accumulation was comparable in those lines to the other lines. Hence, this observation is a subject for further investigation. In a recent study, cabbage line BN3383 showed higher expression of MYB29 (Bol008849), ST5c and FMOGS-OX5 compared to other three cabbage inbred lines but that particular line exhibited comparatively lower levels of total glucosinolates (Robin et al., 2016) indicating that expressions of certain biosynthesis genes were not always consistent with higher accumulation of particular glucosinolates from the relevant biosynthesis pathways.

\section{Accumulation of Indolic GBS in Cabbage Lines Resistant to Blackleg Disease Is Triggered by Increased Expression of Biosynthesis Genes}

ST5a genes take part in secondary modifications of desulfoglucosinolates for the biosynthesis of GBS (Figure S1, Liu et al., 2014; Yi et al., 2015). Concentrations of both GBS and NGBS, which have a proven role in antifungal responses in plants, increased in the resistant line BN4303 in response to 00-100s, and this was associated with a remarkable upregulation of ST5a (Bol026200), CYP81F4 (Bol032712), CYP81F4 (Bol032714), and CYP81F2 (Bol026044) (Figure 5). In a previous study, treatment with MeJA led to a 2,400-fold increase in CYP81F4 in broccoli and a 10-fold increase in cabbage (Yi et al., 2016), suggesting that resistance is mediated via signaling pathways involved in indolic glucosinolate metabolism. ST5a (Bol026200) and CYP81F2 (Bol026044) were also upregulated in the moderately resistant interaction between BN4303 and 03-02s and CYP81F4 (Bol032712) was upregulated in the moderately resistant BN4098 $\times 00-100 \mathrm{~s}$ interaction (Figure 5), suggesting that these genes are associated with the enhanced accumulation of indolic glucosinolates in these interactions. Sotelo et al. (2016) also reported a similar association between $C Y P 81 F 2$ expression and GBS levels in B. oleracea.

By contrast, accumulation of indolic GBS and NGBS and few other aliphatic glucosinolates were noted in susceptible combinations, coupled with upregulation of some notable genes, for example: CYP81F4 genes (Figures 6A,C). These observations raise the question of whether the abundance of intact glucosinolates at a particular time point always reflects their physiological functions. Abundance of glucosinolates in leaf tissues at a particular time-point can be a consequence of simultaneous activation of biosynthesis and catabolism by myrosinases, which can provide upregulation of the bioactive form of the compounds at a particular time point.

\section{Increased Expression of CYP81F2 Leads to Accumulation of MGBS and Is Associated with Moderate Blackleg Resistance in Adult Cabbage Plants}

MGBS levels have previously been reported to increase by $30-$ $47 \%$ in response to L. maculans infection in Brassica napus after 5-8 days of inoculation (Wretblad and Dixelius, 2000). In an in vitro study, Mithen et al. (1986) also reported anti-fungal activity for MGBS along with two other glucosinolates, SIN and GBS. Here, we observed an increase in MGBS in BN4098 after 00-100s inoculation (Figure 2). The facts that BN4098 showed moderate resistance to $00-100 \mathrm{~s}$ and that levels of none of the aliphatic glucosinolates increased suggest a role for MGBS in conferring resistance in this particular interaction. Since CYP81F2 (Bol026004) and CYP81F4 (Bol032712, Bol032714), which are involved in methoxylation and the conversion of GBS to 4-MGBS, are up-regulated in this genotype $\times$ isolate combination, it is likely that both the gene and the glucosinolate play roles in conferring resistance to BN4098 to 00-100 s. Our 
conclusion is consistent with findings of Bednarek et al. (2009) that CYP81F2 (Bol026004) and the myrosinase PEN2 induce antifungal defense (Figure 5).

\section{CONCLUSIONS}

Glucosinolate profiling and expression analysis of glucosinolaterelated genes in response to blackleg infection identified a direct association between the genes and their corresponding glucosinolates in 3-month-old cabbage plants as supported by both heat map and correlation analyses. This study revealed that the simultaneous, pathogen-induced accumulation of both aliphatic GIV and GER and indolic GBS and NGBS were associated with resistance to blackleg disease in a genotypespecific manner in cabbage. Different glucosinolate profiles were associated with different levels of resistance in a genotypeand isolate-specific manner. Although the presence of certain glucosinolates of either the aliphatic or indolic class was associated with moderate resistance, only the presence of both was associated with complete resistance. The glucosinolates and their corresponding genes identified in this study are candidate genetic and biochemical determinants of resistance and could be tested in efforts to improve blackleg resistance in cabbage.

\section{REFERENCES}

Abdel-Farid, I. B., Jahangir, M., Mustafa, N. R., Van Dam, N. M., Van den Hondel, C. A., Kim, H. K., et al. (2010). Glucosinolate profiling of Brassica rapa cultivars after infection by Leptosphaeria maculans and Fusarium oxysporum. Biochem. System. Ecol. 38, 612-620. doi: 10.1016/j.bse.2010. 07.008

Agerbirk, N., Olsen, C. E., and Sørensen, H. (1998). Initial and final products, nitriles, and ascorbigens produced in myrosinase-catalyzed hydrolysis of indole glucosinolates. J. Agric. Food Chem. 46, 1563-1571. doi: 10.1021/jf9708498

Andreasson, E., Wretblad, S., Granér, G., Wu, X., Zhang, J., Dixelius, C., et al. (2001). The myrosinase-glucosinolate system in the interaction between Leptosphaeria maculans and Brassica napus. Mol. Plant Pathol. 2, 281-286. doi: 10.1046/j.1464-6722.2001.00076.x

Ballinger, D. J., and Salisbury, P. A. (1996). Seedling and adult plant evaluation of race variability in Leptosphaeria maculans on Brassica species in Australia. Austr. J. Exp. Agric. 36, 485-488. doi: 10.1071/EA9960485

Barth, C., and Jander, G. (2006). Arabidopsis myrosinases TGG1 and TGG2 have redundant function in glucosinolate breakdown and insect defense. Plant J. 46, 549-562. doi: 10.1111/j.1365-313X.2006.02716.x

Bednarek, P., Piślewska-Bednarek, M., Svatoš, A., Schneider, B., Doubský, J., Mansurova, M., et al. (2009). A glucosinolate metabolism pathway in living plant cells mediates broad-spectrum antifungal defense. Science 323, 101-106. doi: 10.1126/science.1163732

Bekaert, M., Edger, P. P., Hudson, C. M., Pires, J. C., and Conant, G. C. (2012). Metabolic and evolutionary costs of herbivory defense: systems biology of glucosinolate synthesis. New Phytol. 196, 596-605. doi: 10.1111/j.1469-8137.2012.04302.x

Benderoth, M., Textor, S., Windsor, A. J., Mitchell-Olds, T., Gershenzon, J., and Kroymann, J. (2006). Positive selection driving diversification in plant secondary metabolism. Proc. Natl. Acad. Sci. U.S.A. 103, 9118-9123. doi: 10.1073 /pnas.0601738103

Brader, G., Mikkelsen, M. D., Halkier, B. A., and Tapio Palva, E. (2006). Altering glucosinolate profiles modulates disease resistance in plants. Plant J. 46, 758-767. doi: 10.1111/j.1365-313X.2006.02743.x

Brader, G., Tas, É., and Palva, E. T. (2001). Jasmonate-dependent induction of indole glucosinolates in arabidopsis by culture filtrates of the

\section{AUTHOR CONTRIBUTIONS}

IN, JP, and AR conceived of and designed the study. AR managed and inoculated the experimental plants, collected samples, prepared cDNA, performed the qPCR analysis, prepared samples for HPLC and wrote the manuscript. $\mathrm{MH}$ carefully commented on a draft of the manuscript. HK conducted the HPLC analysis. GY and RL assisted with the cDNA preparation and $\mathrm{qPCR}$ analysis.

\section{ACKNOWLEDGMENTS}

We thank the Asia Seed Co., Ltd., Republic of Korea for providing $B$. oleracea seeds. This study was supported by the Center for Horticultural Seed Development (Golden Seed Project no. 213007-05-1-CG100) of the Ministry of Agriculture, Food and Rural Affairs in the Republic of Korea (MAFRA).

\section{SUPPLEMENTARY MATERIAL}

The Supplementary Material for this article can be found online at: https://www.frontiersin.org/articles/10.3389/fpls.2017. 01769/full\#supplementary-material

nonspecific pathogen Erwinia carotovora. Plant Physiol. 126, 849-860. doi: 10.1104/pp.126.2.849

Buxdorf, K., Yaffe, H., Barda, O., and Levy, M. (2013). The effects of glucosinolates and their breakdown products on necrotrophic fungi. PLOS ONE 8:e70771. doi: 10.1371/journal.pone.0070771

Calmes, B., N'Guyen, G., Dumur, J., Brisach, C. A., Campion, C., Iacomi, B., et al. (2015). Glucosinolate-derived isothiocyanates impact mitochondrial function in fungal cells and elicit an oxidative stress response necessary for growth recovery. Front. Plant Sci. 6:414, doi: 10.3389/fpls.2015.00414

Chew, F. S. (1988). "Biological effects of glucosinolates," in Biologically Active Natural Products ACS Symposium Series (Washington, DC: American Chemical Society), 155-181. doi: 10.1021/bk-1988-0380.ch012

Del Rio, L., and Ruud, S. (2013). In vitro sensitivity of Leptosphaeria maculans to azoxystrobin. Can. J. Plant Pathol. 36:258.

Dilmaghani, A., Balesdent, M. H., Rouxel, T., and Moreno-Rico, O. (2010). First report of Leptosphaeria biglobosa (blackleg) on Brassica oleracea (cabbage) in Mexico. Plant Dis. 94, 791-791. doi: 10.1094/PDIS-94-6-0791C

Dilmaghani, A., Gout, L., Moreno-Rico, O., Dias, J. S., Coudard, L., Castillo-Torres, N., et al. (2013). Clonal populations of Leptosphaeria maculans contaminating cabbage in Mexico. Plant Pathol. 62, 520-532. doi: 10.1111/j.1365-3059.2012.02668.x

Doughty, K. J., Porter, A. J. R., Morton, A. M., Kiddle, G., Bock, C. H., and Wallsgrove, R. (1991). Variation in the glucosinolate content of oilseed rape (Brassica napus L.) leaves. Ann. Appl. Biol. 118, 469-477. doi: 10.1111/j.1744-7348.1991.tb05648.x

Fahey, J. W., Zalcmann, A. T., and Talalay, P. (2001). The chemical diversity and distribution of glucosinolates and isothiocyanates among plants. Phytochemistry 56, 5-51. doi: 10.1016/S0031-9422(00)00316-2

Fitt, B. D., Brun, H., Barbetti, M. J., and Rimmer, S. R. (2006). "World-wide importance of phoma stem canker (Leptosphaeria maculans and L. biglobosa) on oilseed rape (Brassica napus)," in Sustainable Strategies for Managing Brassica napus (Oilseed Rape) Resistance to Leptosphaeria maculans (Phoma Stem Canker), (Versailles: Springer Netherlands), 3-15.

Fitt, B. D., Hu, B. C., Li, Z. Q., Liu, S. Y., Lange, R. M., Kharbanda, P. D., et al. (2008). Strategies to prevent spread of Leptosphaeria maculans (phoma stem canker) onto oilseed rape crops in China; costs and benefits. Plant Pathol. 57, 652-664. doi: 10.1111/j.1365-3059.2008.01841.x 
Fraser, M., Hwang, S. F., Ahmed, H. U., Akhavan, A., Stammler, G., Barton, W., et al. (2016). Sensitivity of Leptosphaeria maculans to pyraclostrobin in Alberta, Canada. Can. J. Plant Sci. 97, 83-91. doi: 10.1139/CJPS-2015-0382

Frerigmann, H., and Gigolashvili, T. (2014). MYB34, MYB51, and MYB122 distinctly regulate indolic glucosinolate biosynthesis in Arabidopsis thaliana. Mol. Plant 7, 814-828. doi: 10.1093/mp/ssu004

Frerigmann, H., Piślewska-Bednarek, M., Sánchez-Vallet, A., Molina, A., Glawischnig, E., Gigolashvili, T., et al. (2016). Regulation of pathogentriggered tryptophan metabolism in Arabidopsis thaliana by MYB transcription factors and indole glucosinolate conversion products. Mol. Plant 9, 682-695. doi: 10.1016/j.molp.2016.01.006

Giamoustaris, A., and Mithen, R. (1995). The effect of modifying the glucosinolate content of leaves of oilseed rape (Brassica napus ssp. oleifera) on its interaction with specialist and generalist pests. Ann. Appl. Biol. 126, 347-363. doi: 10.1111/j.1744-7348.1995.tb05371.x

Giamoustaris, A., and Mithen, R. (1997). Glucosinolates and disease resistance in oilseed rape (Brassica napus ssp. oleifera). Plant Pathol. 46, 271-275. doi: 10.1046/j.1365-3059.1997.d01-222.x

Henderson, M. P. (1918). The Black-leg Disease of Cabbage Caused by Phoma lingam (Tode) Desmaz. Madison: University of Wisconsin-Madison. 8, 379-431.

Hiruma, K., Fukunaga, S., Bednarek, P., Piślewska-Bednarek, M., Watanabe, S., Narusaka, Y., et al. (2013). Glutathione and tryptophan metabolism are required for Arabidopsis immunity during the hypersensitive response to hemibiotrophs. Proc. Natl. Acad. Sci. U.S.A. 110, 9589-9594. doi: $10.1073 /$ pnas. 1305745110

Hogge, L. R., Reed, D. W., Underhill, E. W., and Haughn, G. W. (1988). HPLC separation of glucosinolates from leaves and seeds of Arabidopsis thaliana and their identification using thermospray liquid chramatography/mass spectrometry. J. Chromatogr. Sci. 26, 551-556. doi: 10.1093/chromsci/26. 11.551

Hopkins, R. J., van Dam, N. M., and van Loon, J. J. (2009). Role of glucosinolates in insect-plant relationships and multitrophic interactions. Ann. Rev. Entomol. 54, 57-83. doi: 10.1146/annurev.ento.54.110807.090623

Howlett, B. J. (2004). Current knowledge of the interaction between Brassica napus and Leptosphaeria maculans. Can. J. Plant Pathol. 26, 245-252. doi: 10.1080/07060660409507141

Humpherson-Jones, F. M. (1985). The incidence of Alternaria spp. and Leptosphaeria maculans in commercial brassica seed in the United Kingdom. Plant Pathol. 34, 385-390. doi: 10.1111/j.1365-3059.1985.tb01377.x

Kliebenstein, D., Pedersen, D., Barker, B., and Mitchell-Olds, T. (2002). Comparative analysis of quantitative trait loci controlling glucosinolates, myrosinase and insect resistance in Arabidopsis thaliana. Genetics 161, 325-332.

Koh, J. C., Barbulescu, D. M., Salisbury, P. A., and Slater, A. T. (2016). Pterostilbene is a potential candidate for control of blackleg in canola. PLoS ONE 11:e0156186. doi: 10.1371/journal.pone.0156186

Larkan, N. J., Raman, H., Lydiate, D. J., Robinson, S. J., Yu, F., Barbulescu, D. M., et al. (2016). Multi-environment QTL studies suggest a role for cysteine-rich protein kinase genes in quantitative resistance to blackleg disease in Brassica napus. BMC Plant Biol. 16:183. doi: 10.1186/s12870-016-0877-2

Lattanzio, V., Lattanzio, V. M., and Cardinali, A. (2006). Role of phenolics in the resistance mechanisms of plants against fungal pathogens and insects. Phytochemistry Adv. Res. 661, 23-67.

Lee, J., Yang, K., Lee, M., Kim, S., Kim, J., Lim, S., et al. (2015). Differentiated cuticular wax content and expression patterns of cuticular wax biosynthetic genes in bloomed and bloomless broccoli (Brassica oleracea var. italica). Process Biochem. 50, 456-462. doi: 10.1016/j.procbio.2014.12.012

Li, H., Sivasithamparam, K., and Barbetti, M. J. (2003). Breakdown of a Brassica rapa subsp. sylvestris single dominant blackleg resistance gene in B. napus rapeseed by Leptosphaeria maculans field isolates in Australia. Plant Dis. 87, 752-752. doi: 10.1094/PDIS.2003.87.6.752A

Li, Y., Chen, J., Bennett, R., Kiddle, G., Wallsgrove, R., Huang, Y. J., et al. (1999). "Breeding, inheritance, and biochemical studies on Brassica napus cv. Zhougyou 821: tolerance to Sclerotinia sclerotiorum (stem rot)," in Proceedings of the 10th International Rapeseed Congress', Vol. 61. ed N. Wratten (Canberra: PA Salisbury).
Liu, S., Liu, Y., Yang, X., Tong, C., Edwards, D., Parkin, I. A., et al. (2014). The Brassica oleracea genome reveals the asymmetrical evolution of polyploid genomes. Nat. Commun. 5:3930. doi: 10.1038/ncomms4930

Livak, K. J., and Schmittgen, T. D. (2001). Analysis of relative gene expression data using real-time quantitative PCR and the $2^{-\Delta \Delta C T}$ method. Methods 25, 402-408. doi: 10.1006/meth.2001.1262

Manici, L. M., Lazzeri, L., and Palmieri, S. (1997). In vitro fungitoxic activity of some glucosinolates and their enzyme-derived products toward plant pathogenic fungi. J. Agricul. Food Chem. 45, 2768-2773. doi: 10.1021/jf9608635

Marcroft, S. J., Elliott, V. L., Cozijnsen, A. J., Salisbury, P. A., Howlett, B. J., and Van de Wouw, A. P. (2012). Identifying resistance genes to Leptosphaeria maculans in Australian Brassica napus cultivars based on reactions to isolates with known avirulence genotypes. Crop Pasture Sci. 63, 338-350. doi: 10.1071/CP11341

Mithen, R. (2001). Glucosinolates-biochemistry, genetics and biological activity. Plant Growth Regul. 34, 91-103. doi: 10.1023/A:1013330819778

Mithen, R. F., Lewis, B. G., and Fenwick, G. R. (1986). In vitro activity of glucosinolates and their products against Leptosphaeria maculans. Transac. Br. Mycol. Soc. 87, 433-440. doi: 10.1016/S0007-1536(86)80219-4

Mithen, R. F., and Magrath, R. (1992). Glucosinolates and resistance to Leptosphaeria maculans in wild and cultivated Brassica species. Plant Breed. 108, 60-68. doi: 10.1111/j.1439-0523.1992.tb00100.x

Mithen, R., Raybould, A. F., and Giamoustaris, A. (1995). Divergent selection for secondary metabolites between wild populations of Brassica oleracea and its implications for plant-herbivore interactions. Heredity (Edinb). 75, 472-484. doi: 10.1038/hdy.1995.164

Nawaz, I., Iqbal, M., Hakvoort, H. W., Bliek, M., de Boer, B., and Schat, H. (2014). Expression levels and promoter activities of candidate salt tolerance genes in halophytic and glycophytic Brassicaceae. Environ. Exp. Bot. 99, 59-66. doi: 10.1016/j.envexpbot.2013.10.006

Piliponyte-Dzikiene, A., Andriunaite, E., Petraitiene, E., Brazauskiene, I., Statkeviciute, G., and Brazauskas, G. (2015). Genetic diversity and occurrence of Leptosphaeria spp. on Brassica oleracea and B. napus in Lithuania. J. Plant Pathol. 97, 265-271. doi: 10.4454/JPP.V97I2.027

Raman, R., Taylor, B., Marcroft, S., Stiller, J., Eckermann, P., Coombes, N., et al. (2012). Molecular mapping of qualitative and quantitative loci for resistance to Leptosphaeria maculans causing blackleg disease in canola (Brassica napus L.). Theor. Appl. Genet. 125, 405-418. doi: 10.1007/s00122-012-1842-6

Rico, O. M., Trevi-o, A. F., Ruiz, J. L., Flores, D. M., Cova, S. R., and Swartz, G. S. (2001). Characterization and pathogenicity of isolates of Leptosphaeria maculans from Aguascalientes and Zacatecas, Mexico1. Can. J. Plant Pathol. 23, 270-278. doi: 10.1080/07060660109506940

Rimmer, S. R. (2006). Resistance genes to Leptosphaeria maculans in Brassica napus. Can. J. Plant Pathol. 28, S288-S297. doi: 10.1080/07060660609507386

Robin, A. H. K., Larkan, N. J., Laila, R., Park, J. I., Ahmed, N. U., Borhan, H., et al. (2017a). Korean Brassica oleracea germplasm offers a novel source of qualitative resistance to blackleg disease. Eur. J. Plant Pathol. 149, 611-623. doi: 10.1007/s10658-017-1210-0

Robin, A. H. K., Hossain, M. R., Park, J. I., Kim, H. R., and Nou, I. S. (2017b). Glucosinolate profiles in cabbage genotypes influence the preferential feeding of Diamondback moth (Plutella xylostella). Front. Plant Sci. 8:1244. doi: 10.3389/fpls.2017.01244

Robin, A. H. K., Yi, G. E., Laila, R., Yang, K., Park, J. I., Kim, H. R., et al. (2016). Expression profiling of glucosinolate biosynthetic genes in Brassica oleracea $\mathrm{L}$. var. capitata inbred lines reveals their association with glucosinolate content. Molecules 21:787. doi: 10.3390/molecules21060787

Rouxel, T., Penaud, A., Pinochet, X., Brun, H., Gout, L., Delourme, R., et al. (2003). A 10-year survey of populations of Leptosphaeria maculans in France indicates a rapid adaptation towards the Rlm1 resistance gene of oilseed rape. Eur. J. Plant Pathol. 109, 871-881. doi: 10.1023/A:1026189225466

Sanchez-Vallet, A., Ramos, B., Bednarek, P., López, G., Piślewska-Bednarek, M., Schulze-Lefert, P., et al. (2010). Tryptophan-derived secondary metabolites in Arabidopsis thaliana confer non-host resistance to necrotrophic Plectosphaerella cucumerina fungi. Plant J. 63, 115-127. doi: 10.1111/j.1365-313X.2010.04224.x

Sexton, A. C., Kirkegaard, J. A., and Howlett, B. J. (1999). Glucosinolates in Brassica juncea and resistance to Australian isolates of Leptosphaeria maculans, the blackleg fungus. Aust. Plant Pathol. 28, 95-102. doi: 10.1071/AP99017 
Sotelo, T., Velasco, P., Soengas, P., Rodríguez, V. M., and Cartea, M. E. (2016). Modification of leaf glucosinolate contents in Brassica oleracea by divergent selection and effect on expression of genes controlling glucosinolate pathway. Front. Plant Sci. 7:1012. doi: 10.3389/fpls.2016.01012

Sprague, S. J., Balesdent, M. H., Brun, H., Hayden, H. L., Marcroft, S. J., Pinochet, X., et al. (2006). Major gene resistance in Brassica napus (oilseed rape) is overcome by changes in virulence of populations of Leptosphaeria maculans in France and Australia. Eur. J. Plant Pathol. 114, 33-40. doi: 10.1007/s10658-005-3683-5

Stotz, H. U., Sawada, Y., Shimada, Y., Hirai, M. Y., Sasaki, E., Krischke, M., et al. (2011). Role of camalexin, indole glucosinolates, and side chain modification of glucosinolate-derived isothiocyanates in defense of Arabidopsis against Sclerotinia sclerotiorum. Plant J. 67, 81-93. doi: 10.1111/j.1365-313X.2011.04578.x

Tierens, K. F. J., Thomma, B. P., Brouwer, M., Schmidt, J., Kistner, K., Porzel, A., et al. (2001). Study of the role of antimicrobial glucosinolate-derived isothiocyanates in resistance of Arabidopsis to microbial pathogens. Plant Physiol. 125, 1688-1699. doi: 10.1104/pp.125.4.1688

Wink, M. (1988). Plant breeding: importance of plant secondary metabolites for protection against pathogens and herbivores. Theor. Appl. Genet. 75, 225-233. doi: 10.1007/BF00303957

Wretblad, S., and Dixelius, C. (2000). B-genome derived resistance to Leptosphaeria maculans in near isogenic Brassica napus lines is independent of glucosinolate profile. Physiologia Plantarum 110, 461-468. doi: 10.1111/j.1399-3054.2000.1100406.x

Wu, J., Zhao, Q., Yang, Q., Liu, H., Li, Q., Yi, X., et al. (2016). Comparative transcriptomic analysis uncovers the complex genetic network for resistance to Sclerotinia sclerotiorum in Brassica napus. Sci. Rep. 6:19007. doi: 10.1038/srep19007

Yi, G. E., Robin, A. H. K., Yang, K., Park, J. I., Kang, J. G., Yang, T. J., et al. (2015). Identification and expression analysis of glucosinolate biosynthetic genes and estimation of glucosinolate contents in edible organs of Brassica oleracea subspecies. Molecules 20, 13089-13111. doi: 10.3390/molecules2007 13089

Yi, G.-E., Robin, A., Yang, K., Park, J.-I., Hwang, B., and Nou, I.-S. (2016). Exogenous methyl jasmonate and salicylic acid induce subspecies-specific patterns of glucosinolate accumulation and gene expression in Brassica oleracea L. Molecules 21, 1417. doi: 10.3390/molecules21101417

Zhang, B., Hu, Z., Zhang, Y., Li, Y., Zhou, S., and Chen, G., (2012). A putative functional MYB transcription factor induced by low temperature regulates anthocyanin biosynthesis in purple kale (Brassica Oleracea var. acephala $\mathrm{f}$. tricolor). Plant Cell Rep. 31, 281-289. doi: 10.1007/s00299-011-1162-3

Conflict of Interest Statement: The authors declare that the research was conducted in the absence of any commercial or financial relationships that could be construed as a potential conflict of interest.

Copyright (C) 2017 Robin, Yi, Laila, Hossain, Park, Kim and Nou. This is an openaccess article distributed under the terms of the Creative Commons Attribution License (CC BY). The use, distribution or reproduction in other forums is permitted, provided the original author(s) or licensor are credited and that the original publication in this journal is cited, in accordance with accepted academic practice. No use, distribution or reproduction is permitted which does not comply with these terms. 